\title{
Correction to: Direct photo-oxidation and superoxide radical as major responsible for dye photodegradation mechanism promoted by $\mathrm{TiO}_{2}-\mathrm{rGO}$ heterostructure
}

\author{
Gabriela Byzynski $^{1}$ [D $\cdot$ Diogo P. Volanti $^{2} \cdot$ Cauê Ribeiro $^{3} \cdot$ Valmor R. Mastelaro $^{4} \cdot$ Elson Longo $^{5}$
}

Published online: 23 August 2018

(c) Springer Science+Business Media, LLC, part of Springer Nature 2018

\section{Correction to: \\ Journal of Materials Science: Materials in Electronics https://doi.org/10.1007/s10854-018-9799-0}

The original version of this article contains a missed citation in the Material and Methods Section, GO synthesis.

In the paragraph: "All of the chemical reagents were analytical grade. Graphene oxide (GO) was obtained by the Hummers method [17, 18, 50], using natural graphite as a precursor.", the following reference should have been included:
50. T.M. Perfecto, C.A. Zito, D.P. Volanti, Room-temperature volatile organic compounds sensing based on $\mathrm{WO}_{3} \cdot 0.33 \mathrm{H}_{2} \mathrm{O}$, hexagonal- $\mathrm{WO}_{3}$, and their reduced graphene oxide composites. RSC Adv. 6(107), 105171-105179 (2016). https://doi.org/10.1039/c6ra16892b.

The original article can be found online at https://doi.org/10.1007/ s10854-018-9799-0.

Gabriela Byzynski

gabi.byzynski@gmail.com

1 IQ, UNESP, São Paulo State University, Av. Prof. Francisco Degni, 55 - Jardim Quitandinha, Araraquara, SP 14800-900, Brazil

2 IBILCE, UNESP, São Paulo State University, São José do Rio Preto, SP, Brazil

3 Embrapa Instrumentation, São Carlos, SP, Brazil

4 Physics Institute of São Carlos, USP, São Carlos, SP, Brazil

5 DQ, UFSCar, Federal University of São Carlos, São Carlos, SP, Brazil 